\title{
Assessment of Morphology of Wear Particles in Oils for Vehicles
}

\author{
J. Machalíková, M. Sejkorová*, M. Livorová \\ Department of Transport Means and Diagnostics, Univerzity of Pardubice, Czech Republic \\ *Corresponding author: marie.sejkorova@upce.cz \\ F. Krtička \\ Department of mechanics, materials and machine parts, Univerzity of Pardubice, Czech Republic
}

\begin{abstract}
This paper presents the results of a complex analysis of particles isolated from various kinds of oils (automobile engine and transmission oils, hydraulic and compressor oils) and oil filters. Morphological analysis was performed using analytical ferrography in combination with scanning electron microscopy, local electron microanalysis and image analysis. The results are a contribution to the quantitative assessment of processes connected with the wear of parts of vehicles and industrial machinery.
\end{abstract}

KEY WORDS: wear particles, oils, ferrography, scanning electron microscopy, image analysis

\section{INTRODUCTION}

Lubricating oil has many functions: to reduce friction between wear surfaces, to prevent deposition of impurities on the lubricated surfaces and conserve them, to conduct friction heat away, to reduce the penetration of foreign particles from the outside, to prevent aggregation of impurities, to take away wear particles. Its properties have a considerable influence on the speed and intensity of the wear of functional surfaces of the parts - therefore also the lifetime of various machinery equipment. Eventually, the selection of the lubrication mode and optimization of the replacement periods influence the level of operation and investment costs; besides the economical context of lubrication conditions, the safety and environmental aspects are additional important factors. Many mechanisms contribute to the wear of surfaces. These unwanted changes, which occur on the surfaces of the parts by separation of particles as a result of a mechanical action and which are connected with the occurrence of abrasion, may also be accompanied by chemical or electrochemical effects. The evaluation of the number, size, shape, colour, character of the surface and other morphological properties of individual wear particles, especially in combination with the knowledge of their chemical composition, will suggest a lot about which part they are from and which mechanism has caused them. This information can contribute to the elimination of the risk of damage or breakdown of the machine, without the need to demount the equipment.

There are many techniques to enable the acquisition of information about the particles. The following basic methods belong to the most important of them:

- Ferrography utilizes the sedimentation of particles at the flow of an oil sample in a strong non-homogeneous magnetic field. The particles sediment 
in dependence on their size, composition and shape on a suitable pad (glass or plastic), on which it is then possible to evaluate them by means of a microscope ("small" particles of dimensions smaller than $5 \mathrm{~m}$ correspond to normal adhesive wear, "big" particles larger than $15 \mathrm{~m}$ is a warning of approaching damage of the parts which are washed by the analyzed oil).

This method is based on the following two basic presumptions:

1. Each friction pair produces wear particles of specific shapes and sizes, characteristic for the particular mode of wear and the materials of the pair.

2. With the increasing intensity of wear the size of the wear particles increases, their shape changes and so does the ratio between the number of "big" and "small" particles (the authors of most publications, e.g. Straka, 1996; Liu et al., 2000; Krethe, 2001, agree that in the normal mode of wear the ratio between the number of "small" and "big" particles is approximately 500:1, while at escalated wear the ratio increases to 50:1).

- Particle analysis utilising particle counters (LaserNet Fines etc.) enables specifying the sizes of particles contained in oil and to sort the sizes; advanced methods utilizing neural networks are applied during the evaluation. The classifier of particles sorts the particles larger than $20 \mathrm{~m}$ according to their shape and classifies them into 6 groups. When counting the particles, the apparatus is able to distinguish and not to count air bubbles larger than $20 \mathrm{~m}$ and determine the content of free water in the oil.

- Scanning electron microscopy (SEM) enables the observation of the surface of particles isolated from oil or from oil filters. The resulting images are created by means of secondary electrons. The interaction of accelerated electrons with the mass of the sample X-radiation also generates images, which bring a lot of additional information about the composition of the sample; the energy dispersive analysis enables the determination of the element composition of the particle and also the quantitative content of individual elements by comparison with a suitable standard (with the limitations given by the principle of the method).

- Image analysis is a suitable method for quantification and objectification of evaluation of the morphological characteristics of particles; generally, this method enables us to obtain quantitative information of various statistical and morphological characteristics of a digital image and the objects recognized in it. This method has a wide number of possibilities of application in the fields utilizing microscopic technology.

\section{USED EXPERIMENTAL METHOD AND INSTRUMENTATION}

The ferrographic workplace is equipped with ferrograph REO 1 (ReoTrade Ostrava) in a set with the bichromatic trinocular microscope H 6000 (Intraco Micro Tachlovice) and the digital camera Micrometrics 122-CU with a connection to a PC. The observation on the scanning electron microscope VEGA TS 5130 (TESCAN Brno) in the electron microscope laboratory 
DFJP was, for selected samples, supplemented with the analysis on SEM VEGA TS 5130SB with an energy dispersive analyzer in FSI VUT Brno.

Image processing is done by means of the LUCIA G v. 4.82 system (Laboratory Imaging, Prague). The image analysis was used for the evaluation of particles separated on ferrograms and particles isolated from oil filters; for the latter group of particles EDX-analysis was also done. The selected typical particles were separated from oils and filtration cartridges of oil filters of vehicles and industrial equipment (see chapter 3.2).

\section{EXPERIMENTAL WORKS AND THEIR RESULTS}

\subsection{Image Analysis}

The quantitative description of wear particles morphology is an important part of the assessment of relations between the operating conditions and the way, intensity and/or regularity of the wear surfaces.

The basic step in the whole process is always getting a high-quality digitalized image of the microscopic section by means of a USB camera. The image is further modified and analysed by means of the LUCIA program. The key step of the image analysis is segmentation, during which the objects intended for the assessment are marked in the image; then it is possible to perform measuring and determine the required morphological properties of the objects.

Out of the wide range of information that can be obtained by means of image analysis, major attention was paid to the quantification of the shape of individual image objects. Simultaneously additional data were processed, characterizing individual objects, as well as the image as a whole, which can be assessed from the digital images - e.g., the information about the number, area or other size parameters of individual particles, about their global areal content in the analyzed area or in its selected part, etc. The aim of this stage of the works was to algorithmize the quantitative assessment of the selected characteristic parameters of the objects - wear particles, to create and debug the program module of the LUCIA system. The output of the assessment in this stage was the classification of particles according to the type of wear which they can be assigned to. The next prepared stage will focus on defining a practical recommendation to the user of the vehicle/machine.

The processing of the image information on the computer usually starts with elimination of noises and distortion of the image. The basic functions for the image processing used in this stage include the suppression of noise by means of suitable filtration, sharpening of the image, segmentation and recognition of objects (thresholding).

These operations result is a binary image as a data array, containing only the zero (white) or the one (black). Objects are formed by the connection of pixels of one type; the background consists of a set of complements. The connection of pixels is usually defined by means of the nearest neighbours method, i.e., a connection over the edges and over the apexes is acceptable. The smallest structural element contains nine pixels ( 3 rows and 3 columns around the central pixel).

Typical linear morphological operations are: filtration, erosion (removal of selected pixels from the surface of an object), dilatation (adding of selected pixels to the surface of an object), opening (combination of erosion and dilatation) leading to separation of objects, closing (combination of dilatation and erosion) leading to connection of objects, filling of holes in objects and skeletonization, i.e., replacement of an object with its outline.

The next step of the image analysis is the measuring of characteristic attributes of objects. Both individual characteristics (describing individual objects) and textural characteristics (describing the structure of the entire image) are used. 
The information about the shape of the object is, together with the information about the particle size, useful when determining the type and current rate of wear. Professional literature mentions many various shape factors. In this publication we used circularity (Kowandy et al. 2006; Xu et al. 2003; Li at al. 2005) defined as

$$
\text { circularity }=\frac{4 \pi \cdot \text { area }}{\text { circumference }^{2}}
$$

and elongation, defined as the ratio between the maximum and minimum Feret diameter

$$
\text { elongation }=\text { MaxFeret/MinFeret }
$$

(the maximum/minimum Feret diameter is the largest/smallest distance between two parallel tangents of the object).

In the created program module, after the initial delimiting of objects by means of thresholding, the image can be further processed in the binary view. It is then possible to analyze the entire area or individual particles separately. The results of measuring arrays form a table of values.For individual particles it is possible to measure individual parameters by means of commands, the names of which correspond to their functions: Numbers, Length, Radius, Halfaxes, Area, Angle and many others.

The cycle of separation of objects by means of mathematical morphological methods then follows. After the sorting of particles the measuring frame will be specified, which limits the area of further analysis (this is especially advantageous in the case of imperfect segmentation or in the case of a requirement for selection of analyzed particles from a partial segment of the image). Another possibility is manual modification by means of selection from the menus of commands for binary image processing. All options of the binary image modification lead to the paintbrush tool, which removes or completes (models) particles, which could not be captured precisely by means of the modifications. Displaying is accompanied by the information about the total number of objects selected.

This command starts the calculation part of the program macro. If the image is already calibrated (i.e., the scale was assigned to the image), it is possible to work with it. Otherwise the option for continuing with a non-calibrated image is available.

Then the particles are identified by numbers. If the evaluated area contains more than 100 objects, the function includes the query whether or not to perform numbering in the image (for time or capacity reasons, as well as for the clearness of the image).

The output selection menu includes the text output both in the form of tables and in the form of creation of a report in Word, where important data about the analyzed particles are automatically exported to. This also includes the option of graphical output in the form of histograms of the area, circularity and elongation attributes. Each graph also contains selections of various variants of the numbers of classes and their widths.

The output information includes the draft assessment of the type of wear on the basis of the calculated attributes. This draft has a mainly auxiliary (informative) purpose and cannot be taken unconditionally, without a subjective check based on a deep knowledge of the wear issues. However, for the tribotechnics practice, both the calculated data characterizing individual objects or complete images and the proposed final assessment resulting from the data obtained by means of objective procedures, are an important support. 
The above stated functions of the program module were tested on model particles (Figure 1).

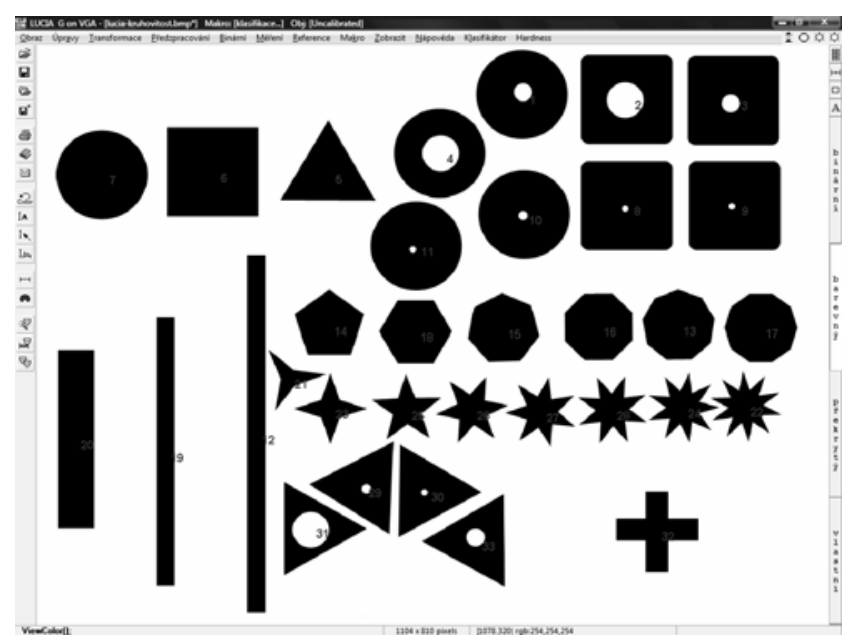

Figure 1: Overview of model shapes of particles

\section{Results of measuring of real particles}

The program module was tested on particles typical for individual types of wear see Figure 2-5 for examples.

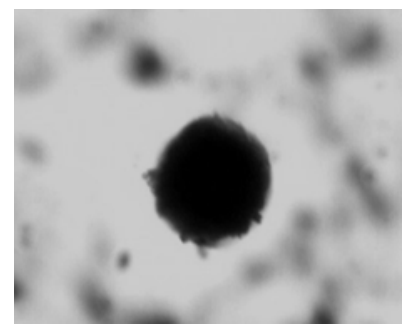

$\mathbf{a}$

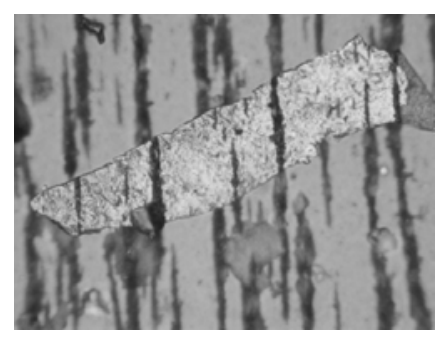

b

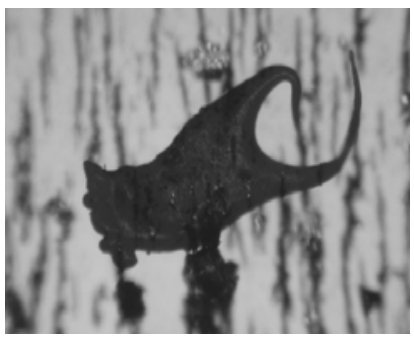

c

Figure 2: Typical particles separated ferrographically from oils

$\mathrm{a}-$ Fatigue particle of typical spherical shape (diameter approx. $20 \mu \mathrm{m}$ )

$\mathrm{b}$ - Laminar particle with visible signs of abrasive wear (length approx. $150 \mu \mathrm{m}$ )

c - Indented particle of cutting wear (max. size approx. $100 \mu \mathrm{m})$
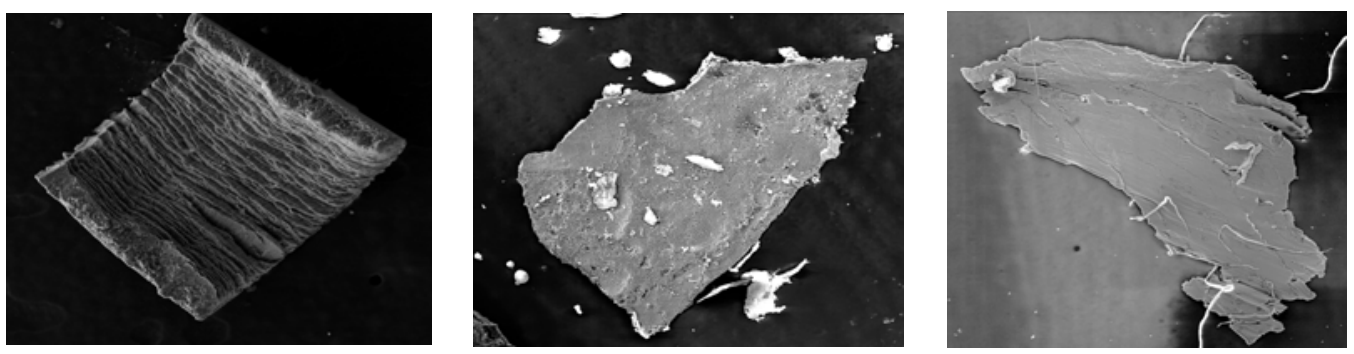

Figure 3: Laminar particle with signs of abrasive wear (max. sizes 200-500 $\mu \mathrm{m}$ ) 

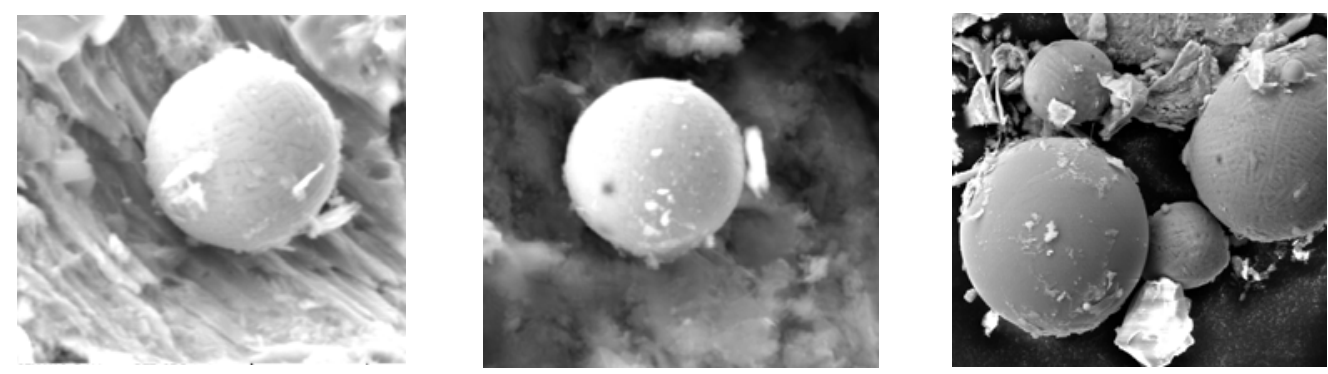

Figure 4: Fatigue particle of typical spherical shape (diameters 10-50 $\mu \mathrm{m}$ )
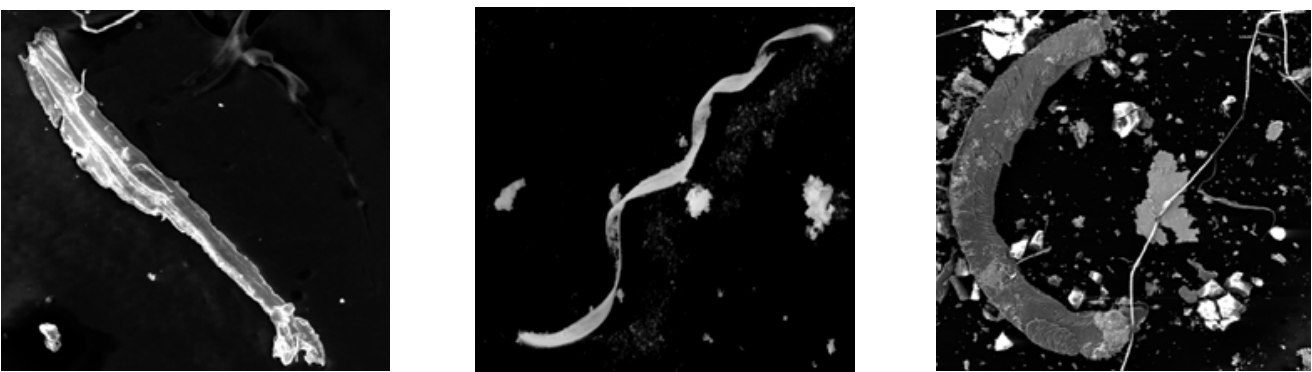

Figure 5: Particles of cutting wear (length 200-600 $\mu \mathrm{m}$ )

Circularity and elongation are the most important attributes, used (together with additional parameters) also for the characterization of the prevailing wearing process

\subsection{Local electron microanalysis}

The selected typical particles isolated from the filtration cartridges of oil filters from the engines of various vehicles (cars and lorries, trucks, the oil filter of a railway motor car 854222 with an internal combustion engine CAT C15) were analyzed on SEM with an energy-dispersive analyzer. The process of isolation of particles is described in detail in (Machalíková \& Schmidová, 2007).

The examined particles can be divided into five groups according to their chemical composition (see Table 1):

Table 1: Composition of typical, most frequent particles

\begin{tabular}{|c|c|c|}
\hline Type & Dominant elements & $\begin{array}{c}\text { Elements contained } \\
\text { in lower concentrations }\end{array}$ \\
\hline 1 & $\mathrm{C}\left(55-85 \%{ }_{\mathrm{at}}\right), \mathrm{O}(30-40 \%$ at $)$ & $\begin{array}{c}\mathrm{Fe}(\text { traces }) \\
\mathrm{Na}, \mathrm{Mg}, \mathrm{Al}, \mathrm{Si}, \mathrm{S}, \mathrm{K}, \mathrm{Ca},\end{array}$ \\
\hline 2 & $\mathrm{Sn}\left(\sim 80 \%_{\mathrm{at}}\right)$ & $\mathrm{Pb}, \mathrm{Cu}, \mathrm{O}, \mathrm{P}, \mathrm{Fe}$ (traces $)$ \\
\hline 3 & $\mathrm{Zn}\left(30-45 \%_{\mathrm{at}}\right), \mathrm{O}(40-47 \mathrm{at}), \mathrm{Al}(\sim 15 \%$ at $)$ & $\mathrm{Fe}, \mathrm{Si}, \mathrm{S}, \mathrm{Cl}, \mathrm{Ca}, \mathrm{Cr}$ \\
\hline 4 & $\mathrm{Fe}(60-70 \%$ at $), \mathrm{O}\left(30-40 \%{ }_{\mathrm{at}}\right)$ & traces of Si, Ca, Cr, Mn, P \\
\hline 5 & $\mathrm{Si}\left(20-30 \%_{\mathrm{at}}\right), \mathrm{O}\left(60-70 \%_{\mathrm{at}}\right), \mathrm{Al}\left(6.46 \%_{\mathrm{at}}\right)$ & $\mathrm{Fe}, \mathrm{Na}, \mathrm{Mg}, \mathrm{K}, \mathrm{Ca}$, \\
\hline
\end{tabular}




\section{Description of typical particles}

Type 1: porous crumbly particles of usually rounded shapes, badly conducting; nondominant elements may be remnants of additives, impurities from the outside, etc. - carbon

Type 2: shiny particles, often with deep grooves, with plastically deformed edges; the main component is stannum - particles from the bearing lining

Type 3: flat thin sharp-edged particles, whose main components are zinc and aluminium; alloys on this basis are used for the increasing of resistance against corrosion and abrasion; particles are released probably from superficial layers of engine parts

Type 4: particles consisting mostly of iron, oxidizing layer on the surface (only $\mathrm{Fe}$ and $\mathrm{O}$ are present in more significant amounts, $\mathrm{Cr}$ and $\mathrm{Mn}$ as microelements) - material of the basic structural element

a - spherical particles mostly of a diameter of $10-50 \mu \mathrm{m}$; spheroids result from fatigue processes

b - narrow flat, even acicular particles, or spirally twisted, plastically deformed particles of cutting wear

c - large flat particles having cracks and pitting corrosion on the surface originate by peeling of the Beilby layer

Type 5: non-conductive particle of silicon dioxide or silicate (these could get into the lubricating system from the outside together with the suction of air).

Note: $\mathrm{Cl}, \mathrm{S}$ and $\mathrm{P}$ may be contained in the remnants of EP-additives, stuck to the particles. Finding of sodium may be connected with intrusion of antifreeze into the oil.

\subsection{Conclusion}

A key part of the work was algorithmization of the process of classification of objects - wear particles. A macro for the LUCIA system was designed and programmed in the $\mathrm{C} / \mathrm{C}++$ language, which enables the analysis and statistical processing of the parameters of individual particles and image arrays. The program macro accelerates, objectifies and simplifies the classification process.

A quantitative description of wear particles is an important part of the assessment of relations between the operating conditions and the way, intensity and/or regularity of the wear surfaces. When assessing microscopic images, the use of the image analysis enables one to perform the quantitative determination of parameters of the examined particles quickly and precisely, without any subjective influencing by the person assessing. At the same time this method enables information to be obtained not only about the basic parameters of the particles, but also data which would be very difficult or even impossible to get in the case of the classical way of assessment - especially the information enabling the quantitative assessment of the particles' shapes.

Obviously, the possibility of burdening the results of the image analysis with errors must always be taken into account, e.g., the limitations caused by the digitalization of the image and problem imaging and separation of very small particles in the digital image, elimination 
of surface defects (scratches, stains, etc.) of the underlying foil, overlapping of the particles on the ferrogram, etc.

This paper verified the possibilities of the use of image analysis as a method suitable for the quantification of data, obtained by means of selected advanced instrumental methods for the classification of the wear of the engine plant. The results of the paper prove that the used combination of methods, i.e., image analysis, analytical ferrography and electron microscopy, may contribute to the extension of possibilities of tribotechnical diagnostics.

In addition, five basic types of particles contained in lubricating oils and oil filters of vehicles and industrial engine plants were defined according to their chemical composition and characteristic morphology.

The examination of wear particles, based on the combination of several methods, creates conditions for obtaining comprehensive information about the process of operating wear of oils, as well as of the mechanisms lubricated by them.

This paper was elaborated within the research project MSM 0021627502.

\section{REFERENCES}

Straka, B., 1986, Motorové oleje a tribotechnická diagnostika naftových motori̊. Praha: NADAS.

Liu, Y., Liu, Z., Wen, S. and Xie, Y., December 2000, Motion analysis on the particles in a magnetic field detector. Tribology International. Volume 33, Issue 12, pp. 837 - 843.

Krethe, R., July-Aug. 2001, Possibilities and frontiers of ferrography. Tribologie und Schmierungstechnik. Vol. 48, no. 4, pp. 48-54.

Kowandy, C., Richard, C., Chen, Y-M., Tessier, J-J., October 2006, Correlatio between the tribological behaviour and wear partije morphology-case of grey cast iron 250 versus Graphite and PTFE. Wear 262, pp. 996-1006.

Xu, R., Di Guida, O. A., February 2003, Comparison of sizing small particles using different technologies. Powder Technology 132, pp. 145- 153.

Li, M., Wilkinson, D., Patchigolla, L., June 2005, Determination ofnon-spherical particle size distribution from chord length measurements. Part 2: Experimental validation, Chemical Engineering Science 60, pp. 4992 - 5003.

Machalíková, J. \& Schmidová, E., 2007, Morfologie otěrových částic. Sborník 13. mezinárodní konference REOTRIB 2007 - Kvalita paliv a maziv. Velké Losiny 30. 5. - 1. 6. 2007., VŠCHT Praha, pp. 87-95, ISBN 987-80-7080-011-9. 